\title{
A trade-off design of microstrip broadband power amplifier for UHF applications
}

\author{
Mohamed Ribate ${ }^{1}$, Rachid Mandry ${ }^{2}$, Jamal Zbitou $^{3}$, Larbi El Abdellaoui ${ }^{4}$, Ahmed Errkik ${ }^{5}$, \\ Mohamed Latrach ${ }^{6}$, Ahmed Lakhssassi ${ }^{7}$ \\ $\mathbf{1 , 2 , 3 , 4 , 5}$ LMTEE, FST of Settat, Hassan $1^{\text {st }}$ University, Morocco \\ ${ }^{6}$ Microwave Group ESEO Angers, France \\ ${ }^{7}$ Quebec University, Canada
}

\begin{tabular}{l}
\hline \hline Article Info \\
\hline Article history: \\
Received May 6, 2019 \\
Revised Sep 29, 2019 \\
Accepted Oct 8, 2019
\end{tabular}

\section{Keywords:}

Binomial transformer

Broadband biasing

Broadband power amplifier

Impedance matching

Microstrip

UHF band

\section{Corresponding Author:}

Mohamed Ribate,

Mechanical, Energy, Electronics and Telecommunication Laboratory (LMEET),

Faculty of Sciences and Techniques,

Hassan 1st University, University Complex, Casablanca Road, Km 3.5, B.O Box 577, Settat, Morocco.

Email: ribate.mohamed@gmail.com

\begin{abstract}
In this paper, the design of a Broadband Power Amplifier for UHF applications is presented. The proposed BPA is based on ATF13876 Agilent active device. The biasing and matching networks both are implemented by using microstrip transmission lines. The input and output matching circuits are designed by combining two broadband matching techniques: a binomial multi-section quarter wave impedance transformer and an approximate transformation of previously designed lumped elements. The proposed BPA shows excellent performances in terms of impedance matching, power gain and unconditionally stability over the operating bandwidth ranging from 1.2 $\mathrm{GHz}$ to $3.3 \mathrm{GHz}$. At $2.2 \mathrm{GHz}$, the large signal simulation shows a saturated output power of $18.875 \mathrm{dBm}$ with an output $1-\mathrm{dB}$ compression point of 6.5 $\mathrm{dBm}$ of input level and a maximum PAE of $36.26 \%$.
\end{abstract}

Copyright $(2020$ Institute of Advanced Engineering and Science. All rights reserved.

\section{INTRODUCTION}

Nowadays, the world as we know it would be unimaginable without Microwave and Radio Frequency electronics. At home, on our phones, in our cares or everywhere, we receive signals from satellites (Satellites TV receivers) or from Global Positioning Systems (GPS), as well as from base stations. The RFID (Radio Frequency Identification) devices becoming more and more deployed in our life and finding use in the non-line-of-sight applications. Indeed, almost every communication system has some sort of transceiver, and intrinsically a power amplifier (PA) running in one of the following bands defined by IEEE standard 521-1984: $\mathrm{L}-\mathrm{S}-\mathrm{C}-\mathrm{X}$ or Ku band [1-4].

In fact, PA applications finding use in a broad range of fields including detection and navigation applications (radars, GPS...), telecommunication, medical microwave imaging, avionics, microwave induction heating and many other applications. As a result, the PA considerations may extremely differ in design, architecture and technological requirements [5-13]. However, the rapid evolution of the wireless communications driven particularly by the growing demand to transmit an increasing amount of data, and the subsequent system level specifications, besides the growing need of broad bandwidth has resulted in an increased regard in Broadband Power Amplifiers (BPAs). Such components can replace multiple narrowband PAs with a single device, and consequently reduce the hardware research and develop costs owing to the incompatibility of the new and old wireless communication standards. [14-19] 
In order to improve the broadband performance, various architectures and configurations of BPAs have been developed including balanced configurations, distributed structures and traveling wave approach besides several matching techniques mostly based on optimization algorithms such as Real Frequency Technique (RFT) and the subsequent Simplified RFT (SRFT), filter-type design and the load-pull technique [20-22]. For the traveling wave or distributed PA approach, the broad bandwidth, linearity and flat gain are achieved by applying a linear design method. However, the drawback of this technique resides in the high number of components deployed to reach the same performance as a single PA, and this results in large size, low efficiency levels and high cost. On the other hand, the balanced structure has good VSWR and gain flatness over about a two octave bandwidth, but the main weakness of such configuration lies in the higher noise figure and the lower Power Added Efficiency (PAE) due to the additional loss in the coupler. For the RFT, SRFT and filter type design, the main drawback of those techniques is resulted in the use of matching networks based on lumped elements (inductors, capacitors and resistors) which must afterwards be transformed into distributed structures. However, in a broad frequency band, this transformation is very tedious and presents various difficulties [23-26].

In this work, a novel and simple BPA configuration is introduced, which cover the mainstream wireless communication standards running in Ultra High Frequency (UHF) band from 1.2 GHz to 3.2 GHz. The proposed BPA is implemented on FR4 substrate and based on GaAs ATF13876 active device. In order to achieve the broadband performance various matching techniques are used in parallel. The first technique is based on multi-section binomial transformer while the second techniques is an approximate transformation of previously synthesized lumped element matching networks into transmission line matching networks. The proposed circuit compares favorably with the contemporary state-of-the-art.

This paper is organized as follows: in section 2, the proposed Broadband Power Amplifier design is described including, topology, broadband biasing circuit and matching techniques applied in this work. Section 3 is devoted to the simulation results, while the concluding statements are summarized in section 4.

\section{THE PROPOSED BROADBAND POWER AMPLIFIER DESIGN METHOD}

Whether characterized as narrowband, wideband, high efficiency, low noise, high power or otherwise, the aim of an RF power amplifier is to provide a finite positive power gain over the operating frequency band. In other words, the main task of an RF PA is to amplify the power level of the signal at its input up to a predefined level at its output over the operating bandwidth. From a practical standpoint, the PA design is usually a trade-off, attempting to realize various conflicting requirements including gain flatness vs broad bandwidth, low distortion vs high output power or efficiency vs linearity. Referring to Figure 1, a typical single stage RF power amplifier consists of a single RF active device, connected to the source and the load through an input and output matching circuits respectively, and DC supplied through a DC bias network. Both the source and the load having the same system characteristic impedance $\mathrm{Z}_{0}$

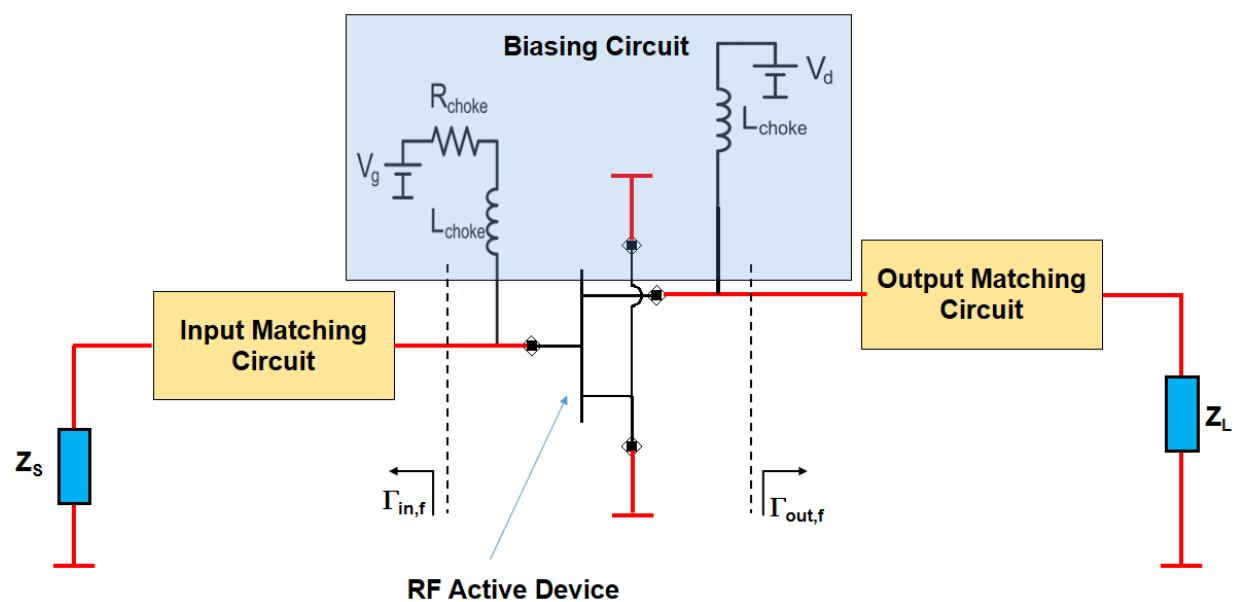

Figure 1. Single active device power amplifier block diagram 


\subsection{Broadband matching networks synthesis}

In high frequencies, due to the natural mismatching of the active device with the source and load impedances, the use of impedance matching networks is indispensable, if not, a part of the electrical signal propagated through the PA will be reflected. In other words, to provide a maximum transfer of the RF power from the input port to the output port through the RF active device, an input matching network must be placed between the latter and the input port, besides an output matching network between the active device and the output port.

On the other hand, the main driven in the BPA design is the need for broad bandwidth. Consequently, the synthesized impedance matching networks must cover a bandwidth as broad as possible. Basically, the impedance matching circuits are designed according to the targeted application as well as the desired operating frequency, and this resulted in various matching techniques and schemes, mostly based on approximation equations, that can be used in order to reach the broadband performance.

At high frequencies, in spite of the lumped element matching networks are intuitive and allows various options for design, excepting an MMIC, it is usually very difficult to implement on a PCB substrate. On the contrary, the matching circuits based on transmission lines, in particular on microstrip technology, are easy to implement on PCB substrate. For this reason, the first broadband matching technique used in this work is an approximate transformation of lumped element matching networks into microstrip matching networks. This transformation can be realized by swapping the lumped elements with transmission lines Figure 2 illustrates the microstrip transmission lines that can replace the synthesized lumped element matching network.
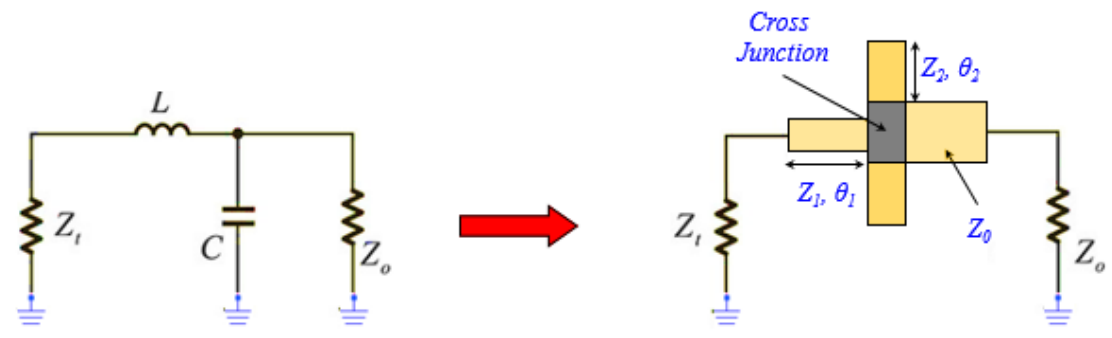

Figure 2. Transformation of lumped element matching circuit into microstrip matching circuit

The microstrip line having characteristic impedance $Z_{1}$ and length $\theta_{1}$ can be considered as a series inductor L, while the two parallel-connected open microstrip stubs with characteristic impedance $\mathrm{Z}_{2}$ and length $\theta_{2}$ can be regarded as shunt capacitor C. $Z_{1}, Z_{2}, \theta_{1}$ and $\theta_{2}$ values can be approximately calculated by the help of (1) and (2):

$$
\begin{array}{llr}
X_{1}=Z_{1} \tan \left(\theta_{1}\right) \approx \omega L & \text { With } & \theta_{1}=\beta l_{1} \\
\mathrm{X}_{2}=\frac{Z_{2}}{2 \tan \left(\theta_{2}\right)} \approx \omega C & \text { and } & \theta_{2}=\beta l_{2}
\end{array}
$$

Since the variables in (1) are $\mathrm{Z} 1$ and $\theta_{1}$, there are two degrees of freedom in implementing the inductor value. The higher characteristic impedance $\mathrm{Z} 1$ is, the closer to an inductor it will be. Similarly, the two degrees of freedom are also valid for (2) and the lower characteristic impedance $\mathrm{Z} 2$ is, the closer it can be implemented as a shunt capacitor.

It is worth noting that the field of the cross-junction depicted in Figure 2 may be influenced when an external circuit is directly connected to the matching network, especially, a coaxial connector. However, to avoid this, a transmission line having the same characteristic impedance Z0 is added. The second broadband matching technique used in this work is the multi-section quarter wave transformer. The schematic of the latter is shown in Figure 3, in which the characteristic impedance of the load ZL is transformed to the feed line impedance Z0. The transformer is composed of discrete transmission lines sections having dissimilar characteristic impedances, but their electrical lengths $\beta l$ are identical, which are assumed to be a quarter wave length at the center frequency f0 of the operating bandwidth. Since the transformer is symmetrical, the return loss coefficients at the junctions between sections are associated as:

$$
\left|\Gamma_{0}\right|=\left|\Gamma_{N}\right| ;\left|\Gamma_{1}\right|=\left|\Gamma_{N-1}\right| ; \ldots
$$




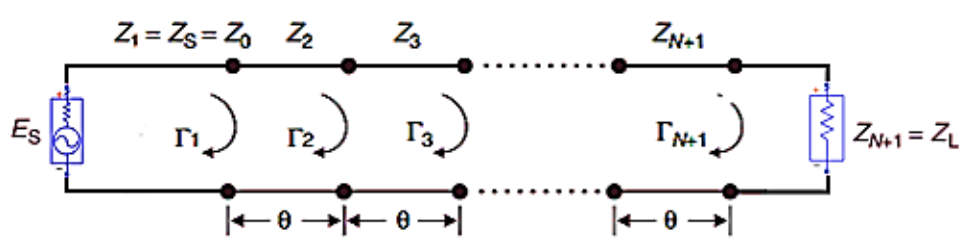

Figure 3. Multi-section quarter wave impedance transformer

Practically, two multi-section quarter wave impedance transformers are widely known, namely Chebyshev and Binomial []. In this work, we adopt the Binomial transformer, which is based on approximate theory. The fractional bandwidth of the binomial transformer illustrated in Figure 3 is given by:

$$
\frac{\Delta f}{f_{0}}=\frac{2\left(f_{0}-f_{m}\right)}{f_{0}}=2-\frac{\pi}{4} \cos ^{-1}\left|\frac{2 \rho_{m}}{\left.\ln { }^{Z_{L} / Z_{0}}\right)}\right|^{1 / N}
$$

Where $\rho_{m}$ is the tolerable reflection coefficient in the passband and $\mathrm{N}$ is the number of sections. The section impedances can be approximately calculated by using (4), defined as:

$$
\ln \frac{Z_{n+1}}{Z_{n}}=2 \rho_{n}=2^{-N} C_{n}^{N} \ln \frac{Z_{L}}{Z_{0}} \quad \text { Where: } \quad C_{n}^{N}=\frac{N !}{(N-n) ! n !}
$$

Where $\rho n$ is the reflection coefficient at the junction between $\mathrm{Zn}$ and $\mathrm{Zn}+1, C_{n}^{N}$ are the binomial coefficients, and $\mathrm{Zn}$ and $\mathrm{Zn}+1$ are the impedances of the $\mathrm{nth}$ and $(\mathrm{n}+1)$ th sections respectively.

\subsection{Broadband microstrip biasing circuitry design}

At RF frequencies, the biasing circuitry design take an important part in the design of the power amplifier. In fact, it provides for the active device the sufficient bias conditions in terms of voltage and current, and therefore guarantee a maximum performance of the whole circuit. Basically, there are various biasing configuration that can be used for this purpose. Simplified microwave biasing circuits as shown in Figure 4.

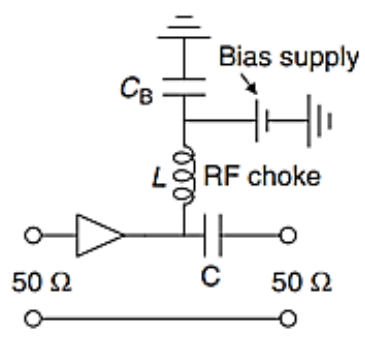

(a)

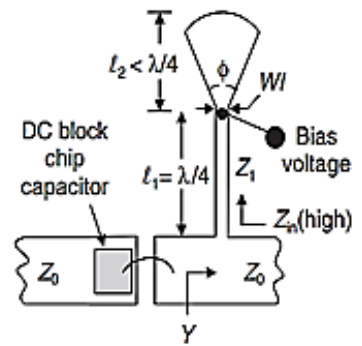

(b)

Figure 4. Simplified microwave biasing circuits: (a) lumped element biasing. (b) microstrip biasing

Typically, a microwave biasing network consists of an RF choke and DC block as shown in Figure 4 (a). However, at RF frequencies, the RF choke are usually implemented by using a high impedance transmission line as shown in Figure 4 (b). The aim of RF choke is to prevent the RF signal from leaking into the biasing network. As a result, the RF chock is designed in a such a way that present a very high impedance in the operating frequency band. Similarly, the DC block is assumed that present a short circuit at the operational bandwidth.

In this work, the biasing circuit is an integral part of the output matching network. Moreover, we adopt the microstrip biasing technique because, as mentioned above, it is easy to implement on PCB substrate besides it provides a broad bandwidth and the capacitor value must be selected such that the $w C=2 \pi f C$ is very high. 


\subsection{Stability considerations}

Fundamentally, any power amplifier must meet the stability conditions in the operating frequency band, otherwise, the unavoidable parasitic effects are enough to provide oscillations and therefore turned the power amplifier into an oscillator. Two stability factor are widely used for the purpose to fulfill the unconditionally stability namely Rollet factor k and Bodway factor B1, defined by the following:

$$
\begin{aligned}
& B_{1}=1+\left|S_{11}\right|^{2}+\left|S_{22}\right|^{2}-|\Delta|^{2}>0 \\
& k=\frac{1+|\Delta|^{2}-\left|S_{11}\right|^{2}-\left|S_{22}\right|^{2}}{2\left|S_{12} S_{21}\right|}>1
\end{aligned}
$$

Where

$$
\Delta=S_{11} S_{22}-S_{12} S_{21}
$$

From (5) and (6), the unconditionally stability is accomplished only when the following conditions are fulfilled simultaneously: $\mathrm{k}>1, \mathrm{~S}_{22}<1$ and $\mathrm{B}_{1}>0$. By using the ideas reported above, the proposed Broadband Power Amplifier schematic circuitry is illustrated in Figure 5.

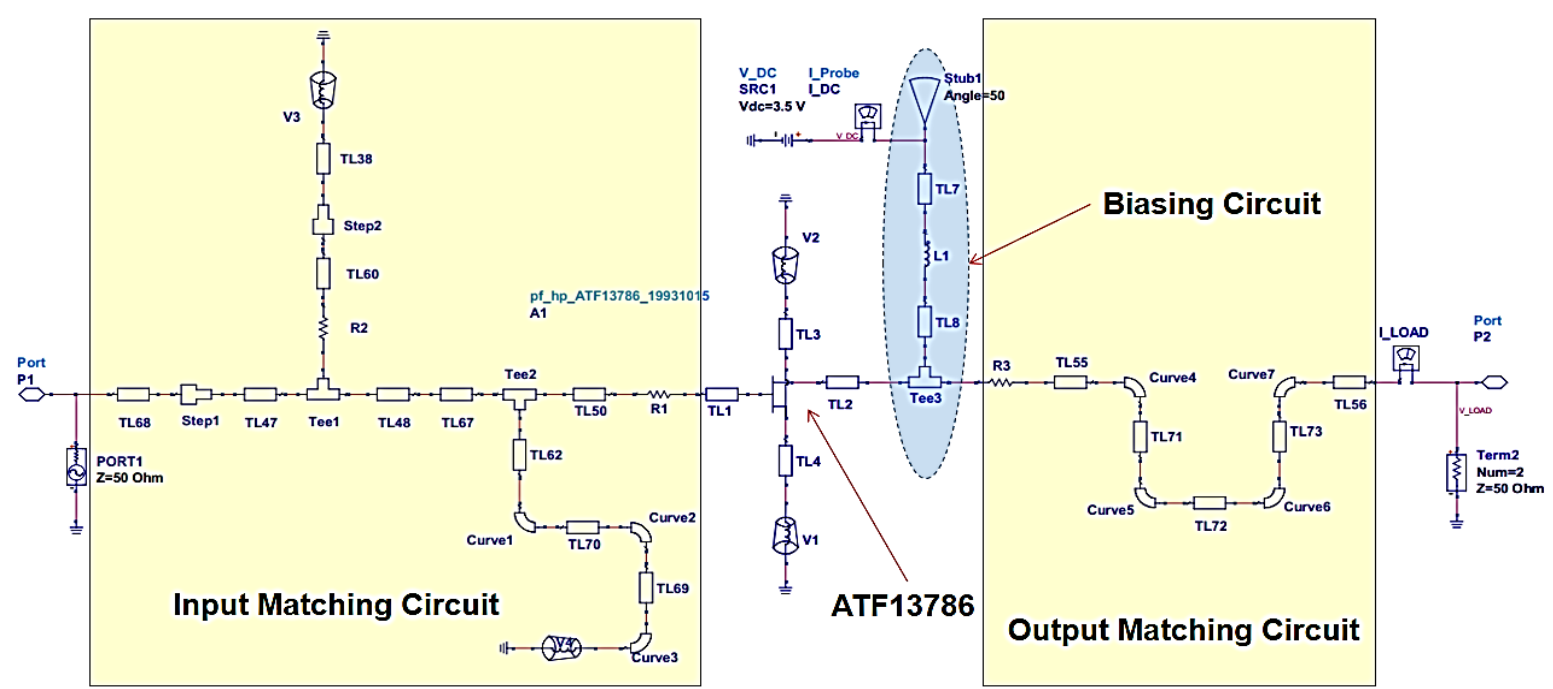

Figure 5. The proposed single stage microstrip BPA schematic circuitry

\section{RESULTS AND DISCUSSIONS}

\subsection{Small signal simulation and stability analysis}

At microwave frequencies, it is very difficult to perform a two port network by using the immittance parameters because there are based on short/open circuit terminations. As a result, the characterization of the proposed BPA is based on the Scattering parameters which are defined from reflected and incident waves. In this work, the source and load terminations both having the same impedance $Z=50 \Omega$. The scattering parameters of the proposed BPA are simulated by using ADS software.

The simulated Small-Signal S-parameters are illustrated in Figure 6. As it can be noted, both the input and output reflection coefficients $\left(S_{11} \& S_{22}\right)$ are strictly under $-11 \mathrm{~dB}$, while the maximum value reached by the revers transmission coefficient (S12) is $-20 \mathrm{~dB}$ over the frequency band ranges from $1.2 \mathrm{GHz}$ to $3.2 \mathrm{GHz}$. The small signal power gain $\left(\mathrm{S}_{21}\right)$ also changes between a maximum value of $16.17 \mathrm{~dB}$ and a minimum value of $8 \mathrm{~dB}$ over the operating frequency band. From a practical standpoint, the revers transmission coefficient $\left(S_{12}\right)$ represents the internal feedback of a two port network, and the smaller value of $\mathrm{S} 12$, the greater is the degree of stability and isolation of a given two-port network.

The curves of stability factors are shown in Figure 7. From (5) and (6), we can clearly assume that the unconditionally stability of the proposed BPA is fulfilled over the wider operating bandwidth. The small signal simulation shows satisfying results in terms of broadband impedance matching, power gain and stability over the wider bandwidth ranging from $1.2 \mathrm{GHz}$ to $3.2 \mathrm{GHz}$. 

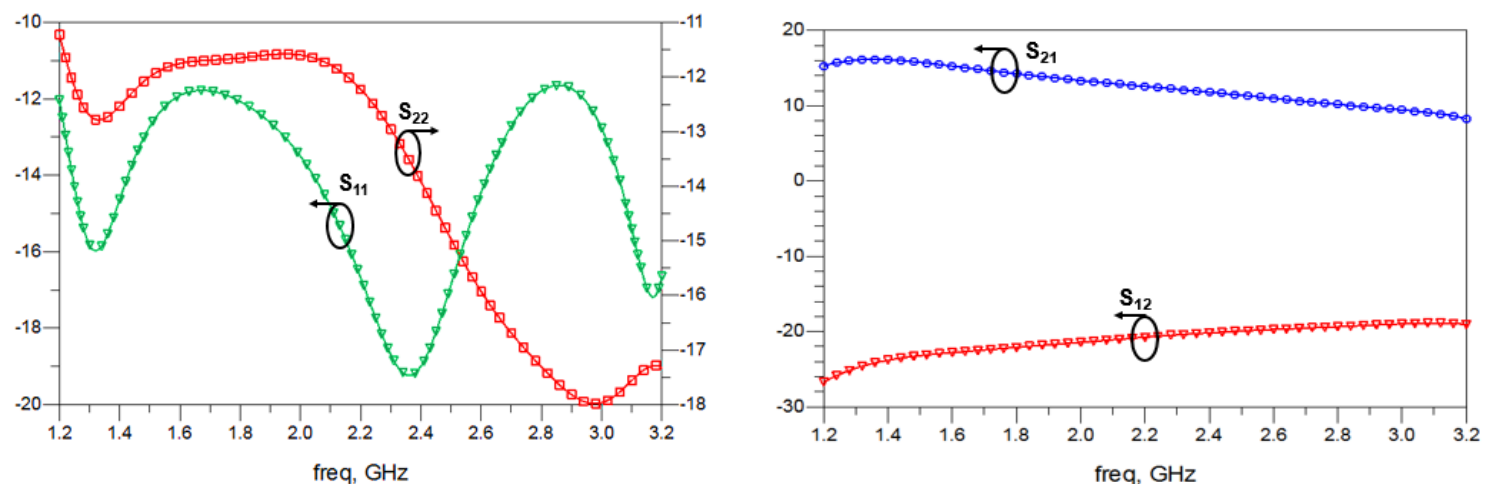

Figure 6. Input return loss $\left[\mathrm{S}_{11}\right]$, output return loss $\left[\mathrm{S}_{22}\right]$, power gain $\left[\mathrm{S}_{21}\right]$ and revers transmission coefficient $\left[\mathrm{S}_{12}\right]$ versus frequency
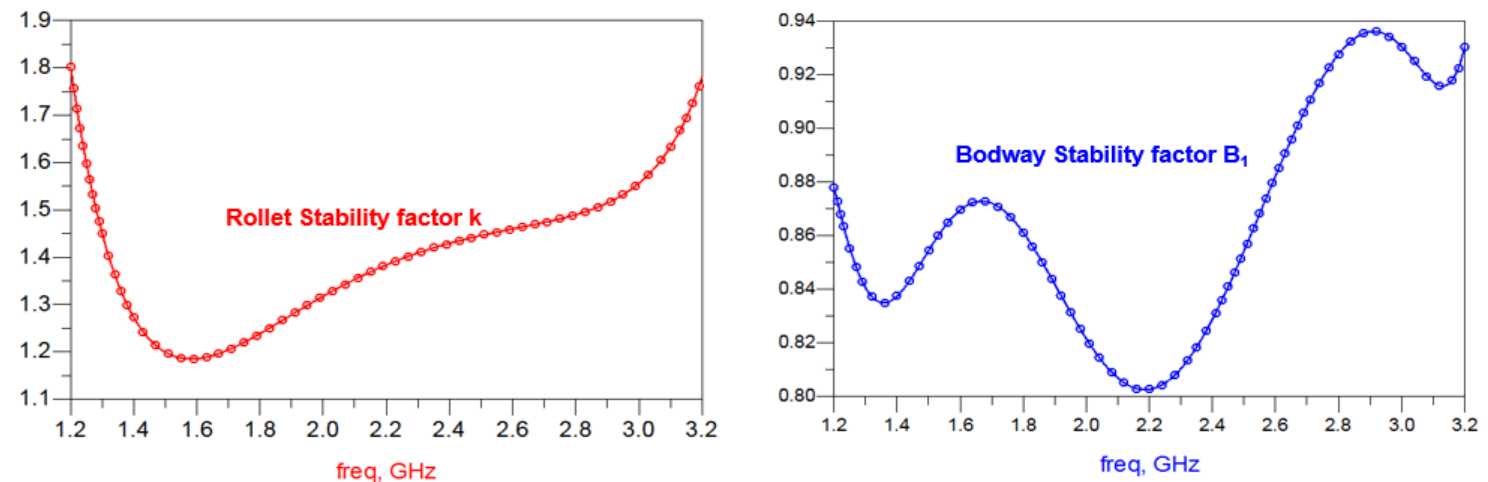

Figure 7. Rollet and bodway stability factors versus frequency

\subsection{Large signal performance}

The large signal performance of the proposed BPA has been simulated at $2.2 \mathrm{GHz}$. Basically, the output power is defined as the power delivered toward the external load in a given frequency band. However, while the input power increase, we eventually reach a point where the output power can anymore keep increasing linearly with the input power. This point is point is named the $1-\mathrm{dB}$ compression point, in which, the output power deviates from its linear region by 1-dB. Figure 8 (a) shows the simulated output power and the 1-dB compression point of the of the proposed BPA. This latter reaches a saturated output power of $18.875 \mathrm{dBm}$, this corresponding of $77.17 \mathrm{~mW}$, with an output 1-dB compression point of $6.5 \mathrm{dBm}$ of input level.

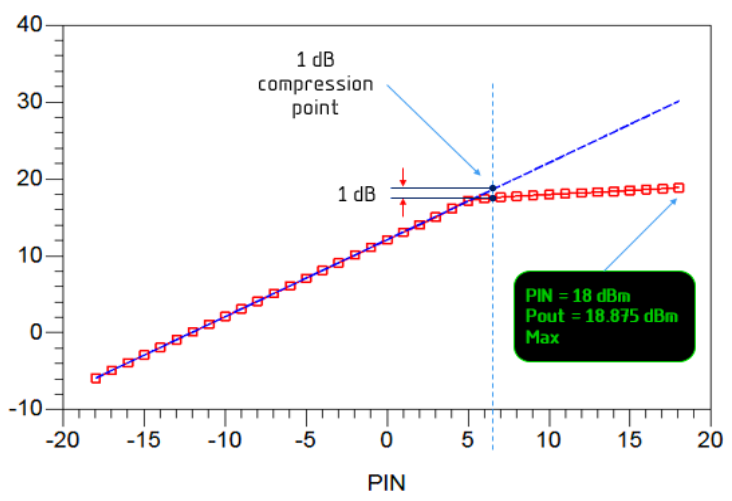

(a)

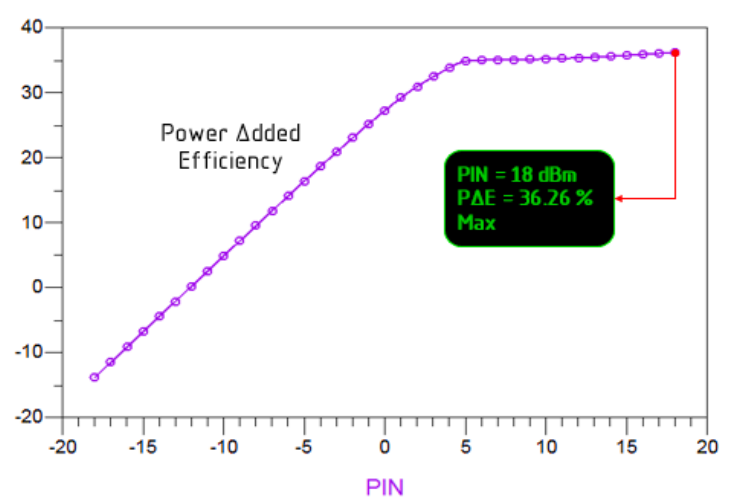

(b)

Figure 8. Output power (a) and power added efficiency (b) versus input power 
Moreover, from a practical point of view, in a given frequency band, a power amplifier may be considered as a device able to transform the DC power from supplies into RF power. The effectiveness of this transformation is usually evaluated by means of Power Added Efficiency (PAE). The simulated PAE is shown in Figure 8 (b). The proposed BPA achieves a maximum PAE of $36.26 \%$.

In order to provide a general overview of the deployed matching techniques capabilities and the proposed BPA performance, a comparison with the similar contemporary state-of-the art BPAs is performed. Table 1 summarizes a performance comparison between the proposed BPA and the recently reported BPAs. To author's best acknowledge, the proposed BPA provides competitive results in terms of broadband matching, power gain, output power and PAE.

Table 1. Performance comparison between the proposed BPA and state - of -the art BPAs

\begin{tabular}{cccccccc}
\hline PAs & $\begin{array}{c}\text { Freq } \\
{[\mathrm{GHz}]}\end{array}$ & $\begin{array}{c}\text { Gain } \\
{[\mathrm{dB}]}\end{array}$ & $\begin{array}{c}\text { Psat } \\
{[\mathrm{dBm}]}\end{array}$ & $\begin{array}{c}\text { PAE } \\
{[\%]}\end{array}$ & $\begin{array}{c}\text { S11 } \\
{[\mathrm{dB}]}\end{array}$ & $\begin{array}{c}\text { S22 } \\
{[\mathrm{dB}]}\end{array}$ & $\begin{array}{c}\text { Supply } \\
{[\mathrm{V}]}\end{array}$ \\
\hline$[27] 2015$ & $1.9-2.7$ & 11 & 28.1 & 13.7 & - & - & - \\
2.5 \\
{$[28] 2016$} & $1.8-2.8$ & 28 & 25 & 6.1 & $-12 \mid-25$ & $-9 \mid-19$ & 5 \\
{$[5] 2017$} & $1-4$ & 12.15 & 14.8 & 20 & $-9 \mid-24$ & $-8 \mid-18$ & 3.5 \\
{$[20] 2018$} & $1.1-3$ & 14.9 & 17.14 & 14.9 & $-10 \mid-35$ & $-10 \mid-25$ & 3 \\
{$[14] 2019$} & $1-12.5$ & 10 & - & - & $-5 \mid-15$ & $-5 \mid-15$ & $V_{d}=2$ \\
This Work & $1.2-3.2$ & 16.31 & 18.875 & 36.26 & $-11 \mid-19$ & $-12 \mid-18$ & $V_{g}=-0.15$ \\
\hline
\end{tabular}

\section{CONCLUSION}

A Broadband Power Amplifier operating in the frequency band ranges from $1.2 \mathrm{GHz}$ to $3.2 \mathrm{GHz}$ has been described in this paper. The proposed BPA is based on ATF13876 active device and cover the mainstream applications running in UHF band. The deployed matching and biasing techniques shows an excellent input and output matching as well as an unconditionally stability over the overall operating bandwidth. The large signal simulation exhibits an output 1-dB compression point of $6.5 \mathrm{dBm}$ of input level with a saturated output power of $18.875 \mathrm{dBm}(77.17 \mathrm{~mW})$ and a maximum PAE of $36.26 \%$. The proposed BPA provides competitive results compared with the contemporary state-of-the-art BPAs.

\section{REFERENCES}

[1] B. Mladen B et al., Power Amplifiers for the $S$-, $C$-, $X$ - and Ku-bands, Switzerland: Springer International Publishing, 2016.

[2] P.B. Khannur et al., "A Universal UHF RFID Reader IC in 0.18- $\mu \mathrm{m}$ CMOS Technology," IEEE Journal of SolidState Circuits, vol. 43, no. 5, pp. $1146-1155,2008$.

[3] M. Ribate et al., "1.25 GHz - 3.3 GHz Broadband Solid State Power Amplifier for L and S Bands Applications" International Journal of Electrical and Computer Engineering, vol. 9, no. 5, 2019.

[4] IEEE Std, 521-1984, "IEEE Standard Letter Designations for Radar-Frequency Bands,” IEEE, 1984.

[5] M. Ribate, et al., "GaAs FET Broadband Power Amplifier for L and S Bands Applications," Proceeding of the 2nd Intl. Conference on Computing and Wireless Communication Systems (ICCWCS), Morocco, 2017.

[6] Hosako et al., "At the Dawn of a New Era in Terahertz Technology," Proceeding of IEEE, vol. 95, no. 8, 2007.

[7] M. John, et al., "Microwave Power Applications," IEEE Transactions on Microwave Theory and Techniques, vol. 50, no. 3, pp. $975-985,2002$.

[8] GC. Giakos, et al., "Noninvasive imaging for the new century," IEEE Instrumentation and Measurement Magazine, vol. 2, no. 2, pp. 32-35, 1999.

[9] A. Rosen, et al., "Applications of RF/microwaves in medicine," IEEE Transactions on Microwave Theory and Techniques, vol. 50, no. 3, pp. 963-974, 2002.

[10] EC. Fear, et al., "Stuchly MA. Confocal microwave imaging for breast cancer detection: localization of tumors in three dimensions," IEEE Transactions on Biomedical Engineering, vol. 49, no. 8, pp. 812-822, 2002.

[11] EC. Fear, et al., "Microwaves for breast cancer detection?," IEEE Potentials, vol. 22, no. 1, pp. 12-18. 2003.

[12] LQ. Huo, et al., "Active microwave imaging. I. 2-D forward and inverse scattering methods," IEEE Transactions on Microwave Theory and Techniques, vol. 50, no. 1, pp. 123-133. 2002.

[13] IT. Rekanos, et al., "Microwave imaging in the time domain of buried multiple scatters by using an FDTD-based optimization technique," IEEE Transactions on Magnetics, vol. 39, no. 3, pp. 1381-1384, 2003.

[14] M. Fernandez, et al., "On the Design of Broadband Hybrid Amplifiers Using Non-Uniform Transmission Lines as Impedance Matching Networks," IEEE Access, vol. 7, pp. 19670 - 19677, 2019.

[15] FH. Raab, et al., "RF and microwave power amplifier and transmitter technologies - part 1," High Frequency Electronics, vol. 2, pp. 22-36, 2003.

[16] J. Fang., et al., "3.5 GHz WiMAX GaN Doherty power amplifier with second harmonic tuning," Microwave and Optical Technology Letters, vol. 54, no. 11, pp. 2601-2605.,2012. 
[17] G. Watkins, et al., "The impact of power amplifier turn-on characteristics in cognitive radio networks," Microwave Journal, vol. 57, no. 2, pp. 86-92, 2014

[18] D. Ye, et al., "Tradeoff Design of Broadband Power Amplifier in Doherty Configuration Utilizing a Novel Coupled-Line Coupler," Progress in Electromagnetics Research C., vol. 48, pp. 11-19, 2014.

[19] R. Wagner., "3G power amplifiers: moving from GaAs to CMOS," Microwave Journal, vol.5, no. 4, pp. 44-48, 2012.

[20] M. Ribate, et al., "Broadband GaAs FET Power Amplifier for L and S Bands Applications," International Journal of Intelligent Engineering and Systems, vol. 11, no. 5, pp. 96-105, 2018.

[21] A. Eroglu, Introduction to RF power amplifier design and simulation, US: CRC Press, 2016.

[22] P. Colantonio, et al., High efficiency RF and microwave solid state power amplifiers, UK: John Wiley \& Sons Ltd, 2009.

[23] C. Poole, et al., Microwave active circuit analysis and design, US: Elsevier Ltd, 2016.

[24] IJ. Bahl, Fundamentals of RF and microwave transistor amplifiers, New Jersey: John Wiley \& Sons, 2009.

[25] MK. Kazimierczuk, RF Power Amplifiers, 2nd edition, Ohio: John Wiley \& Sons, 2015.

[26] MS. Khan, et al., "A Novel Two-Stage Broadband Doherty Power Amplifier for Wireless Applications". IEEE Microwave and Wireless Components Letters, vol. 28, no. 1, pp. 40-42, 2018.

[27] B. Francois, et al., "Highly linear fully integrated wideband RF PA for LTE advanced in 180-nm SOI," IEEE Transactions on Microwave Theory and Techniques, vol. 63, no. 3, pp. 649-658, 2015.

[28] C.Q. Chen, et al., "1.8-2.8 GHz Highly Linear Broadband Power Amplifier for LTE-A Application," Progress in Electromagnetics Research C, vol. 66, pp. 47-54, 2016.

\section{BIOGRAPHIES OF AUTHORS}
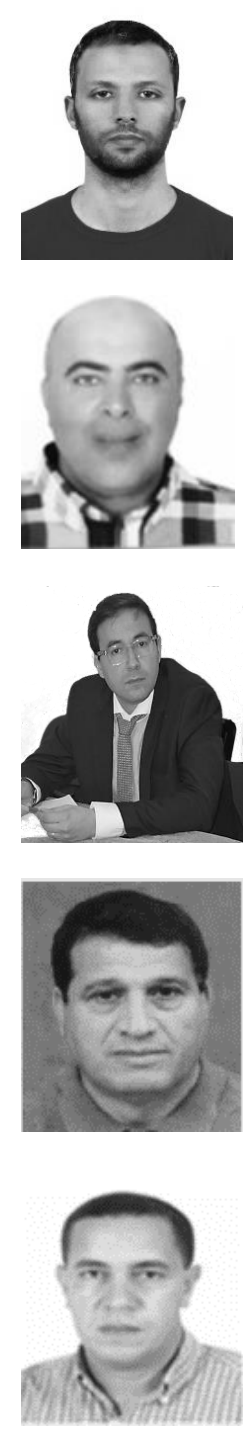

Mohamed Ribate received B.S degree and Master Eng. in Networking and Telecommunication engineering from Hassan $1^{\text {st }}$ University, Settat, Morocco in 2013 and 2015 respectively. He is currently working towards his Ph.D. in Microwave and RF Electronics at FST of Settat, University Hassan 1st, Morocco since November 2015. His research interest includes study, design and implementation of Broadband Power Amplifier using Micro Strip Technology.

Rachid Mandry was born in Casablanca, Morocco in 1967. He received the Ph.D. in nuclear physics and particles from Claude Bernard University, Lyon, France in 1993. He is currently an associate Professor of Physics in FST, University Hassan 1st, Settat, Morocco. He is involved in the design of hybrid, active and passive microwave circuits.

Jamal Zbitou was born in Fes, Morocco, in June 1976. He received the Ph.D. degree in electronics from Polytech of Nantes, the University of Nantes, Nantes, France, in 2005. He is currently an associate Professor of Electronics in FST University Hassan 1st, Settat, Morocco. He is involved in the design of hybrid, monolithic active and passive microwave electronic circuits.

Larbi El Abdellaoui was born in Tiflet, Morocco, in 1961. He received the Ph.D. degree in electronics from the University of Metz, in 1994, France. He is currently an associate Professor of Electronics in Faculty of sciences and techniques, University Hassan 1st, Settat, Morocco. He is involved in the design of hybrid, monolithic active and passive microwave electronic circuits

Ahmed Errkik was born in July 1960 in Morocco. He received the Ph.D. degree in physics from the University of Technology Compiegne (UTC), France. He is currently an associate Professor of physics in FST University Hassan 1st, Settat, Morocco. He is involved in the design of hybrid, monolithic active and passive microwave electronic circuits. 


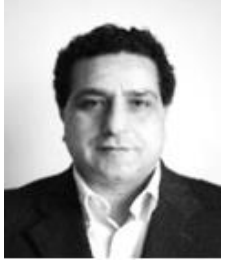

Mohamed Latrach was born in Douar Ksiba, Sless, Morocco, in 1958. He received the Ph.D. degree in electronics from the University of Limoges, Limoges, France, in 1990. He is currently a Professor of microwave engineering with the Ecole Suprieure d'Electronique de l'Ouest (ESEO), Angers, France, where his research involves RF and microwaves. His field of interest is the design of hybrid, monolithic active, and passive microwave circuits, metamaterials, LH materials, antennas and their applications in wireless Communications.

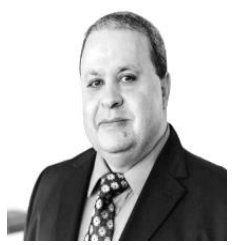

Ahmed Lakhssassi received the B.Eng. and M.Sc. in electrical engineering from University of Quebec à Trois-Rivières, Quebec, Canada in 1988 and 1990 respectively. He also received the $\mathrm{Ph}$. D in Energy and Material sciences in 1995 from INRS-Energie et Matériaux, Quebec, Canada. His research interest is the fields of bio-heat thermal modeling. Also, his research interest is in Design of fully automated tool for porting analog and mixed signal circuits within different technology nodes. 